\title{
Predestinasi
}

Volume 13, No. 1, Juni 2020, Hal. 15- 26

ISSN (Print): 1978-9351

\section{An Appraisal of Alvin Goldman's Social Epistemology}

\author{
Elias Ifeanyi E. Uzoigwe \\ Department of Philosophy, University of Calabar, Nigeria \\ e-mail: uzoigweelis@gmail.com
}

\begin{abstract}
This work is aimed at giving an insight into the issues raised by Goldman in his argument that social epistemology is 'real epistemology'. Goldman wants to convince the mainstream epistemologists and the philosophical world in general that social epistemology is real epistemology by distinguishing between three forms of social epistemology: revisionist, preservationist, and expansionist. These three forms of social epistemology construed and proposed by Goldman differ in how they relate to the basic assumptions of traditional/classical epistemology. While acknowledging the various authors for their divergent views and contributions to social epistemic discourse, this work holds that though Goldman, more than any other social epistemologist, raised a fresh perspective in social epistemology, yet, there is a missing link in his submission. Goldman's preservationist social epistemology, which he argued is "real epistemology", fails to give at least, a spotlight on what this work calls historical social epistemology. This does not in any way downplay Goldman's giant stride in awakening epistemologists from their slumber which led some scholars to include issues like analytic social epistemology, diagnostic social epistemology, naturalistic social epistemology, and political social epistemology in the epistemic lexicon; and by so doing, expanding the frontiers of the epistemic domain of philosophical enterprise. It is the position of this research that Goldman's social epistemology elicited a renewed interest in epistemologists and scholars alike in the social dimension of knowledge. This work employs historical, conceptual, contextual, and textual methods of analyses.
\end{abstract}

Keywords: Social Epistemology; Revisionism; Preservationism; Expansionism; Historical Social Epistemology

\section{INTRODUCTION}

The social dimension of knowledge has been unduly neglected, and scholars, especially those of the epistemic divide consider it imperative to strike the balance; and as a result, socialising movements also emerged, because, for them, knowledge has a social perspective. The movement does not reject a concern for individual epistemic decision making, but it finds at least equal importance in the study of epistemic decision making in social contexts (Goldman and Blanchard, 2018, p. 6). Similarly, until recently the orientation of both historical and contemporary epistemology has been heavily individualistic. The emphasis has been on choices among belief, disbelief, and agnosticism (suspension of judgment) that confront individual epistemic agents. Such agents are assumed to observe the world (or their own minds) and reflect 
on the resulting evidence via their own cognitive powers. Such a perspective was dramatized by Descartes 350 years ago, and it has continued to dominate the epistemological scene (Goldman and Blanchard, 2018, p. 6).

Social epistemology (SE) like other contemporary concepts in philosophy has not enjoyed a conventionally acceptable definition. Scholars define social epistemology from a variegated approach of their schools of thought and orientations. Social epistemology can be construed as a broad set of approaches that can be employed in the study of knowledge that conceives human knowledge as a collective achievement. It could be likened to Mbiti's "I am because we are", looking at it from the African context. Another way of characterising social epistemology is that it is an appraisal of the social dimension of knowledge. Sometimes social epistemology is construed as a social justification of belief (Sarachukwuaka 2017, p. 40). From another perspective, SE can be characterised as the evaluation of the social dimensions of knowledge or information. It is sometimes simplified to mean a social justification of knowledge (stanford.library.edu.au. Retrieved 24-9-2019). Social epistemology is associated with the interdisciplinary field of science and technology studies (STS). Goldman describes social epistemology as knowledge derived from one's interactions with another person, group, or society.

Notable among social epistemologists are: Alvin Goldman, Steve Fuller, Thomas Kuhn, Martin Kush, Thomas Blanchard, Edward Craig, John Hardwig and a host of others. However, the perspective of this research is on Alvin Goldman's approach to social epistemology. This does not preclude the fact that the works of the other scholars will be cited along with Goldman's in order to give this work a more academic undertone. It is Goldman's view that there are three forms of social epistemology namely: revisionist, preservationist, and expansionist. Goldman argued that of all these, preservationist social epistemology is 'real epistemology', because it shares some basic features with traditional epistemology. This work says thumbs up for Goldman for his renewed effort and interest and multi in Pavo contributions in this almost forgotten epistemic divide; however, he lost sight of its historical dimension.

\section{A HISTORICAL SURVEY OF SOCIAL EPISTEMOLOGY}

Social epistemology did not happen abruptly. However, it is the thinking of William Alston that the boundaries of epistemology are controversial. Social epistemology can be historically traced back to the Socratic era of philosophical inquiry. The consideration of the social dimension of knowledge in relation to philosophy started in 380 B.C.E with Plato's dialogue: Charmides (Sarachukwuaka 2017, p. 46). In his dialogue, Plato questioned the degree of certainty an unprofessional in a field can have towards a person's claim to be a specialist in that same field. As the findings of dependence on authoritative figures constitute a part of the study of social epistemology, it confirms the existence of the ideology in minds long before it was given its label.

In 1936, Karl Mannheim turned Karl Marx's theory of ideology into an analysis of how the human society develops and functions, and was showcased to the academic world. Marx's theory interpreted the "social" aspect in epistemology to be of a political or sociological nature. Philosophical issues like epistemic value of testimony, the nature and function of expertise, proper distribution of cognitive labour and resources among individuals in the communities and the status of group reasoning and knowledge began to appeal to philosophers in the 1970s.Succinctly put,

The social dimension of knowledge was not pronounced in the ancient, medieval, and modern epochs of philosophical discourse. Though, we cannot deny the fact that Plato's dialogue has something epistemologists can extrapolate from it in to make it a launching 
pad for social epistemology. As it were, it was not until the 1970s that there was a powerful development of interest among philosophers (Sarachukwuaka 2017, p. 79).

\section{THE RISE OF SOCIAL EPISTEMOLOGY IN THE CONTEMPORARY ERA}

It is difficult to say who actually coined the two words "social epistemology" (SE), especially as it is understood in the 21 st century epistemology. What is historically evident is that the term "social epistemology" was used for the very first time in the 1950s by the library scientists namely, Margaret Egan and Jesse Shera. In 1979, Steven Shapin (1994) also employed the term SE (Roy 2016, p. 62). It was not until the late 1980s that its current sense began to emerge. In 1987, the philosophical journal Synthese published a special issue on social epistemology which included two authors that have since taken the branch of epistemology in two divergent directions (Alvin Goldman and O'Connor 2019).

It is remarkable to note that Fuller founded a journal called Social Epistemology: A journal of knowledge, culture, and policy in 1987 and published his first book, Social Epistemology in 1988. Goldman's Knowledge in a Social World was published in 1999. Goldman advocates for a type of epistemology that is sometimes called "veritistic epistemology" because of its large emphasis on truth. This type of epistemology is sometimes seen to side with "essentialism" as opposed to "multiculturalism". But Goldman has argued that this association between veritistic epistemology and essentialism is not necessary (Zanzy 2015, p. 213).

Goldman looks into one of the two strategies of the socialization of epistemology. This strategy includes the evaluation of social factors that impact knowledge formed on true belief. In contrast, Fuller takes preference for the second strategy that defines knowledge influenced by social factors as collectively accepted belief. (Alvin Goldman and O'Connor 2019). In 2012, on the occasion of the 25th anniversary of Social Epistemology, Fuller reflected upon the history and the prospects of the field, including the need for social epistemology to re-connect with the larger issues of knowledge production first identified by Charles Sanders Peirce as cognitive economy and nowadays often pursued by the library and information science. As for the "analytic social epistemology", to which Goldman has been a significant contributor, Fuller concludes that it has "failed to make significant progress owing, in part, to a minimal understanding of actual knowledge practices, a minimised role for philosophers in ongoing inquiry, and a focus on maintaining the status quo of epistemology as a field (Roy 2016, p. 32).

The basic view of knowledge that motivated the emergence of social epistemology as it is perceived today can be traced to the work of Thomas Kuhn and Michel Foucault, which gained acknowledgment at the end of the 1960s. Both brought historical concerns directly to bear on problems long associated with the philosophy of science. Perhaps the most notable issue here was the nature of truth, which both Kuhn and Foucault described as a relative and contingent notion. On this background, ongoing work in the sociology of scientific knowledge (SSK) and the history and philosophy of science (HPS) was able to assert its epistemological consequences, leading most notably to the establishment of the strong programme at the University of Edinburgh. In terms of the two strands of social epistemology, Fuller is more sensitive and receptive to this historical trajectory (if not always in agreement) than Goldman, whose "veritistic" social epistemology can be reasonably read as a systematic rejection of the more extreme claims associated with Kuhn and Foucault (Hilary, 2015, p. 113).

\section{Social Epistemology as a Field within Analytic Philosophy}

As a field within analytic philosophy, social epistemology foregrounds the social aspects of knowledge creation and dissemination. What precisely these social aspects are, and whether 
they have beneficial or detrimental effects upon the possibilities to create, acquire and spread knowledge is a subject of continuous debate (Alvin Goldman and O'Connor 2019). Within the field, "the social" is approached in two complementary and not mutually exclusive ways: "the social" character of knowledge can either be approached through inquiries in inter-individual epistemic relations or through inquiries focusing on epistemic communities. The inter-individual approach typically focuses on issues such as testimony, epistemic trust as a form of trust placed by one individual in another, epistemic dependence, epistemic authority, etc. The community approach typically focuses on issues such as community standards of justification, community procedures of critique, diversity, epistemic justice, and collective knowledge (Alvin Goldman and O'Connor 2019).

Social epistemology as a field within analytic philosophy has close ties to, and often overlaps with feminist epistemology and philosophy of science. While a part of the field engages in abstract, normative considerations of knowledge creation and dissemination, other parts of the field are "naturalized epistemology" in the sense that they draw on empirically gained insights. And while parts of the field are concerned with analytic considerations of a rather general character, case-based and domain-specific inquiries in, e.g., knowledge creation in collaborative scientific practice, knowledge exchange on online platforms, or knowledge gained in learning institutions play an important role (Hilary 2015, p, 117).

\section{ALVIN GOLDMAN'S SOCIAL EPISTEMOLOGY}

As one of the outstanding exponents of social epistemology, Goldman has written extensively on the subject which, as noted above, he construes as a field within analytic philosophy. Among his writings, three remain outstanding as it concerns his position on social epistemology. They include: Knowledge in a Social World (KSW published in 1999), Why Social Epistemology is Real Epistemology (WSERE published in 2001); and another work he titled, Social Epistemology (SE 1999), which he co-authored with Thomas Blanchard, and was later reviewed and modified in 2012.

Goldman (2002) defined social epistemology from two perspectives. According to one perspective, social epistemology is a branch of traditional epistemology that studies epistemic properties of individuals that arise from their relation to others, as well as epistemic properties of groups or social systems. A simple example (of the first sort) is the transmission of knowledge or justification from one person to another. Studying such interpersonal epistemic relations is a legitimate part of epistemology. A very different perspective would associate social epistemology with movements in postmodernism, social studies of science, or cultural studies that aim to replace traditional epistemology with radically different questions, premises, or procedures (Goldman 2019).

\section{IN WHAT SENSE IS SOCIAL EPISTEMOLOGY SOCIAL?}

Analysing further Goldman's contributions to social epistemology, it is considered relevant here to include views which he shared in common with Thomas Blanchard. This view is so dear to Goldman that he recapitulated it in his subsequent works. According to Goldman and Blanchard, there are three ways in which social epistemology can be termed social namely, (a). Interpersonal, (b) Collective, and (c). Institutional

\section{Interpersonal Social Epistemology}

Social epistemology continues to reflect on optimal methods for individual belief formation but specifically considers evidential inputs from other people -their opinions, 
assertions, and arguments. Knowledge, though could be individual based, it is also an interpersonal issue.

\section{Collective Social Epistemology}

Social epistemology commonly acknowledges the existence of collective doxastic-agents such as juries, committees, and other group agents, which make judgments as a function of their members' judgment. It is the members who collectively judge what is to be regarded as knowledge or not.

\section{Institutional social epistemology}

Social epistemology considers communities and societies as systems and institutions with system-level properties that often influence the intellectual output of their members. The ways they organize the epistemic labor-the way they open or close channels of communication for eager or reluctant speakers, thereby encouraging or discouraging assorted modes of information or disinformation propaganda - are enormously significant to the knowledge state of a society (Goldman and Blanchard 2018, p. 6). It is the position of Goldman and Blanchard that,

The criteria for epistemic assessment in social epistemology need not depart dramatically from individual epistemology. Knowledge, truth, rationality, and justification can remain the benchmarks or standards by which to assess both social and individual methods. But social epistemology introduces a new class of methods and epistemology may hold that the social dimension of knowledge creates a need to revise or reformulate the customary concepts of knowledge, rationality, truth, and/or objectivity" (2018, p. 7).

There are three conceptions of social epistemology, which Goldman analysed vis-à-vis classical epistemology. In his own words, "I shall divide conceptions of social epistemology (SE) into three types: (1) revisionism, (2) progressivism, and (3) expansionism. These conceptions will be framed in terms of their relationships to traditional or mainstream epistemology" (Goldman 2019). The three forms differ in how they relate to the basic assumptions of classical epistemology; to wit, that epistemic agents are exclusively individuals; that epistemology clarifies key concepts of epistemic evaluation (such as knowledge or justification); that these concepts are of universal validity; and that concepts of epistemic achievement are linked to an objective and mind-independent truth (Kush 2016, p. 847). Goldman defines social epistemology as knowledge derived from one's interaction with another person, group or society.

\section{Revisionist Social Epistemology}

The revisionist social epistemology, which Goldman technically referred to as 'revisionism' has some missing links with the traditional or classical epistemology. Even Goldman himself construed that it is only aspiring to the mainstream epistemology. He writes, "Under revisionism, I include postmodernism, deconstructionism, social constructionism and various social studies of science, including 'strong programme' in the sociology of science" (Goldman 3). Inspired by the social character of the phenomena they study, these movements in common share a strong rejection of the core tenets of mainstream epistemology. They worked against the notions of truth, objective rationality, and epistemic agent, among other things. A scholar like Richard Rorty (1979) who had earlier announced the demise of epistemology and proposed a vague replacement for it, is an outstanding example of a revisionist thinker in line with Goldman's line of thought. Employing Rorty's exact words, "keep the conversation going rather than to find objective truth" (1979, p. 377). Giving support to Rorty, "truth is a social institution" (Stephen Shapin 1994, p. 6). Truths are not in or of this world, they are not "out 
there' to be discovered but are mere social fabrications or constructions (Latour and Woolgar 1986).

It is important to note that the revisionists use the language of knowledge, but they do not conceive it to be truth-entailing or truth-tracking as Robert Nozick would call it, or factive state. While revisionists often use the language of 'knowledge,' they don't understand it to be truthentailing...In their lexicon knowledge is simply whatever is believed, or perhaps 'institutionalized' belief (Goldman 3). Still, with their deconstructionist mindset, the revisionists reject objective rationality as a fiction of the mind. According to Barnes and Bloor, "there are no context-free or super-cultural norms of rationality" (1982, p. 27).

On the issue of epistemic agents, proponents of revisionism like Harkinson -Nelson construed that only groups or communities qualify as knowers. In his own words, "The collaborators, the consensus achievers, and, in more general terms, the agents, who generate knowledge are the communities and sub-communities, not individuals" (Phillips 2000, p. 13). As a revisionist himself, Martin Kush (2016) called this "communitarian epistemology". Goldman further identified that revisionists might be called social epistemologists by courtesy not only because they dispute the main tenets of traditional epistemology, but also there is a big chasm, a wide gulf between their questions and those that traditionally go by the name epistemology. Goldman maintains that scholars should tread with caution on the boundary between revisionism and mainstream epistemology, especially in recent times. In his own words,

"Our attempt to draw a firm boundary between revisionism and mainstream epistemology may be a bit quick. Recent developments in epistemology and philosophy of language may argue for greater nuance. Is it true, for example, that mainstream epistemology firmly and definitively rejects relativism. Recently the scene has shifted a bit. There is a 'New Age' kind of relativism ...that has gained popularity within analytic philosophy. Perhaps New Age relativism has much in common with what revisionists like Barnes and Bloor have claimed. If so, there may be less distance between revisionism and mainstream epistemology than suggested above. However, we should not exaggerate the degree to which the popularity of New Age relativism closes the gap between revisionism and mainstream analytic epistemology. What Wright calls 'New Age relativism' is a view championed by John MacFarlane (2005), Max Kolbel (2003), and Peter Lasersohn (2005) among others... (2012, p. 251).

From the above analysis, one is not in doubt of the influence Ludwig Wittgenstein had on Goldman. What Goldman has simply done is an epistemic gymnast. One thing is apparent from the findings so far, it is the fact that Goldman is of the view that revisionism is not part of traditional epistemology. To further instantiate this claim,

As far as revisionist SE is concerned, Goldman suggests the traditionalist is right: it does not belong within real epistemology. Revisionists give up most or all of the assumptions of classical epistemology and aim for a "successor" project. Metaphorically speaking, revisionists tear down the building of classical epistemology and build themselves an altogether new intellectual home" (Kush 2016, p. 874).

New Age relativism is primarily a semantical thesis, and as formulated...it does not express everything - or the most important thing - that revisionist relativism means to assert. Revisionist relativism would agree on a central presupposition of New age relativism, namely, that multiple epistemic systems are possible and justification claims can be asserted relative to any of these different systems (Boghossian 2006, p. 414). Revisionist relativism further assents to a thesis, which Boghossian (2006) technically calls 'epistemic nihilism'. Epistemic nihilism holds that 'there are no fact by virtue of which one of these systems is more correct than any of 
the others' (Boghossian 2006, pp. 73, 413). This, according to Goldman, 'is the core thesis of relativism that revisionists advance and mainstream epistemologists dispute (2010, p. 5).

\section{Preservationist Social Epistemology}

In order to adequately prove that preservationism is 'real epistemology', Goldman employed three types of activity studied by mainstream epistemology to support his claims. In his own words,

I shall illustrate preservationism by reference to the three types of activity studied by traditional epistemology, each of which has a social sector. Each social sector of these three parts of epistemology qualifies as 'real' epistemology. The three types of activity in their social variants, are (1) doxastic decision - making with social evidence, (2) gathering social evidence, and (3) speech communication with an informational purport (assertion, debate, argumentation, etc.) (Goldman 2010, p. 6).

\section{Doxastic Decision - Making with Social Evidence}

The major concern of traditional epistemology is the epistemic evaluation of doxastic decision - making (DDM). In general, there is nothing social about DDM. It is the contention of Goldman that the doxastic agent makes use of social evidence. The content of evidential belief concerns other people, because the evidential belief may have contents about what other people have said or written. Again, the evidential beliefs may have contents concerning other people's opinions (or other psychological states), which the doxastic agent may acquire at second or third hand. According to Goldman, "Two lively portions of current epistemology, testimony and peer disagreement focus on the use of social evidence in these ways. Testimony poses the problem: when is a doxastic agent justified in accepting another person's testimony?' This is arguably the fundamental topic of social epistemology...Peer disagreement raises the question of whether rationality requires one to revise one's belief (or degree of belief) if one finds oneself in disagreement with someone else who shares roughly the same evidence and has comparable cognitive abilities. Each topic concerns epistemic justification or reasonability and thereby falls within mainstream epistemology" (2012, p. 6).

Essentially, Goldman is of the view that both social and traditional epistemology comfortably intersects; they are not at rivalry with each other, and thus real epistemology. Preservationist SE is a conservative extension of classical epistemology - and thus it counts as real epistemology. The preservationists add a new storey to the epistemological house but see no need for laying new foundations... The preservationist social epistemology goes beyond classical epistemology, however, in reminding us that we often give vital information or evidence from other human agents (Kush 2016, p. 875).

\section{Gathering Social Evidence}

The gathering of social evidence, within the context of our discourse, is also called 'investigation or inquiry'. It is here that it is made more open and clearer that the philosophy of science is a branch of epistemic discourse. A case in point according to Goldman is that, "In a memorable phase of the philosophy of science Karl Popper defended a falsification approach to scientific experimentation over a verificationist approach" (1962, p. 7). Though a good number of philosophers of science share a common opinion in the theory of testing, is the desideratum of seeking a variety of evidence. This maxim flows from the thesis, shared by many confirmation theorists, that more varied evidence lends greater confirmation to a hypothesis than less varied evidence (Goldman 2012). 
It is not all epistemologists that consent to the view that gathering of evidence is a proper subject for epistemological assessment. Notable among the scholars that oppose the idea is Richard Feldman. He argued that in traditional epistemology as well as in contemporary epistemic discourse, evidence gathering is not a necessary condition. Responding to Feldman, Goldman argues, "To me, this indicates that Feldman's account of our fundamental epistemic goals is inadequate. What is required is a high degree of belief (HDOB)...We have not said anything yet about social evidence gathering specifically. This is a special province of SE under my proposal. It is not essential to SE's viability that there be wholly distinct principles of evidence gathering (or doxastic decision-making) for the social domain" (2012, p. 10-11).

\section{The Social Epistemology of Speech and Communication}

Another type of social epistemic activity is making statements and engaging in argumentative exchange. Such speech activities are social, of course, and the analysis of their epistemic properties is naturally assigned to SE. This cooperative enterprise is, effectively, social - epistemic, so one can view the norms as having both a linguistic and an epistemological origin. Argumentation and dialectic have long been part of the epistemological mix, though often more at the periphery than the centre (Goldman 2012, p. 11).

Goldman calls this analysandum (being justified), which for him, is a property of doxastic states or doxastic agents, which he called personal justification. According to the envisaged approach, it is to be analysed in terms of the posessors's disposition to interact verbally with others in some specified fashion $(2012$, p. 12). The requisite verbal interaction Goldman called interpersonal justifying something one does with interlocutors. Goldman also envisages some kind of imbalance (asymmetries) between the speaker and the hearer, which for him, could be one of the problems of SE of speech and communication. In fact, Goldman doubts if the dialectical approach will succeed in the process of justification.

Argumentative legitimacy is not equivalent to validity (or inductive strength). A prominent fact that needs explaining is that enthymemes, (which are invalid arguments as they stand), are commonly used in everyday speech, yet nobody finds them objectionable. In summary, many forms of SE are unquestionably instances of traditional epistemology. It would be arbitrary and misguided of epistemologists to contend that no part or instance of SE is real epistemology (Goldman 2010).

\section{Expansionist Social Epistemology}

In his effort to prove that social epistemology is real epistemology, Goldman further proposed expansionism (i.e. expansionist social epistemology). By way of expanding the frontiers of social epistemology, he includes the epistemic properties of groups (collective doxastic agents), the influence of social 'systems' and their policies on epistemic outcomes.

\section{Collective Doxastic Agents}

It is the contention of Goldman that in our everyday activities we often speak of collective entities like committees, juries, courts, scientific panels, and governments as making judgments or taking a cognitive stance of one sort or another. Once these kinds of intentional attitudes for collective agents are conceded, shouldn't we reflect on the epistemic properties of these attitudes? Going further Goldman argued, "If an individual's judgment over a set of many propositions can be accessed for their (epistemic) rationality, isn't it appropriate to make similar assessments of a collective agent's judgments? And if epistemologists take an interest in cases that seriously challenge what is rational for the individual, shouldn't epistemologists - social epistemologists take an interest in cases that seriously challenge what is rational for a collective agent? (2012, p. 15). 
In 1993 the issue of collective judgemental rationality was first identified by Kornhauser and Sager. However, the problem of consistency of judgment at the individual level and also at the collective level should not be ruled out. It has been earlier argued that collective agents do not consistently engage in doxastic decision-making. Responding to this Goldman articulates, "I dispute the assumption that collective agents do not engage in doxastic decision-making (DDM). Although collective agents are (presumably) not distinct centres of consciousness, this does not mean that they don't engage in $\operatorname{DDM}(2012$, p. 16).

The above amounts to what Goldman called a paradox of social rationality. Supporting his claim that social epistemology is real epistemology and referring back to preservasionism as a case in point, he then goes much further to ask, "Can there be systematic rational group agents whose judgements are suitably tied to those of their members? If not, what does this imply by epistemic rationality at the collective level? This question is sufficiently novel relative to the epistemological tradition that it cannot be folded into preservationist SE. On the other hand, it is sufficiently continuous with traditional epistemology that it deserves a home somewhere in epistemology. A comfortable home can be found in what I call the expansionist district of SE (2012, p. 17).

\section{Epistemic Evaluation of Social Systems}

It is no longer news, especially in this contemporary era that, many facets of social life feature practices and institutions ostensibly dedicated to epistemic ends, but where one is entitled to wonder whether prevailing practices and institutions are optimal. For Goldman, subjecting such practices and institutions to epistemic evaluation is in order. This position of Goldman, for me, goes further to support the claim that philosophy is the mother/queen of arts and sciences. The systems that have some epistemic dimension that can be termed social include: legal adjudication systems, which though are not being a collective doxastic agent in their own right, such systems are typically guided by a truth-seeking mission. Advancing his argument Goldman articulates, "In the case of the American system, the Supreme Court stated this clearly in Tehan v U.S (1966), 'The basic purpose of a trial is the determination of truth' (2012, p. 18).

\section{Epistemic Rationale for Freedom of Speech}

For Goldman, "Freedom of speech" is the best social arrangement for generating good 'verististic' (true belief) consequences. This goes a long way to show that there are epistemological issues inherent event in the socio-cultural cum political milieu.

The peculiar evil of silencing the expression of an opinion is that it is robbing the human race; posterity as well as the existing generations; those who dissent from the opinion, still more than those who hold it. If the opinion is right, they are deprived of the opportunity of exchanging error for truth; if wrong they lose, what is almost as great a benefit, the clearer perception and livelier impression of truth, produced by its collision with error (Mills 19962, pp. 142-143).

\section{Epistemic Approach to Democracy}

As Goldman's last example of expansionist SE, a driving force behind an important strand of work on epistemic approach is the Condorcet Jury Theorem, discovered in the eighteenth century. The usual and outstanding knock against this system (CJT) is that it reveals that voting per se is not such a significant aspect of democratic procedure. If a Theorist managed to formulate such a set of requirements and showed that satisfying these requirements has a reliabilistically beneficial properties for groups, this would show, by means of epistemology-indeed, social epistemology-that certain features of a system promote an 
important epistemic desideratum, that is, reliability, or increased reliability. Some features of public deliberation would contribute to a group's reliability, thereby providing a basis for a reliabilist rationale for democracy. What Goldman is trying to establish here is that there is epistemic content even in a democratic process of a given society.

\section{CONCLUSION}

From our analysis, especially as it is encapsulated in his work, Knowledge in a Social World, Goldman argues that social epistemology should be seen as complementing rather than replacing traditional epistemology. On this view social epistemology retains traditional epistemology's normative focus on how epistemic practices and systems in terms of their ability to produce "verististc value" (the kind of value we place on having true beliefs). It is quite apparent that Goldman expressed a variety of views in each of his publications from where his social-epistemic views are extrapolated. Just like Wittgenstein, Goldman equally revisited his earlier positions in order to make his brand of thought fit into the 21 st century epistemic discourse. This must have been one of the reasons why he consistently argued in his work, "Is Social Epistemology Real Epistemology", that preservationist social epistemology is indeed real epistemology because it shares some features with traditional epistemology.

As it were, no one has done more for establishing social epistemology as a vibrant aspect of epistemology than Goldman. However, that does not preclude the fact that in some areas his vision of the field is limited. A case in point is his little interest in socio-historical and in fact what this work calls historical social epistemology. He further subsumes diagnostic approaches under revisionism, where this is construed as postmodernist deconstructionism. No doubt, some deconstructionist theories reject the pillars of mainstream epistemology, but that does not suffice to disqualify them as "real epistemology". There is a need to give historical social epistemology (HSE) and diagnostic contributions a prominent place in articulating social epistemology. It is from the thesis and antithesis that Hegel arrived at his synthesis. It is from rationalist and empiricist impasse that Kant articulated his famous synthetic a priori. It is from the Old Testament that the New Testament finds its full meaning. So, there is a need for Goldman in articulating his social epistemic ideas to include historical social epistemology.

\section{REFERENCES}

Barnes, B., \& Bloor, D. (1982). Relativism, rationalism and the sociology of knowledge. Rationality and relativism, Basil Packwell 21-47.

Boghossian, P. (2006). Fear of Knowledge. Against Relativism and Constructivism. Oxford (Clarendon Press) 2006.

Egan, M. E., \& Shera, J. H. (1952). Foundations of a theory of bibliography. The Library Quarterly, 22(2), 125-137.

Goldman, A. (2002). What is social epistemology? A smorgasbord of projects. Pathways to knowledge, 182-204.

Goldman, A. I. (1999). Knowledge in a Social World, Oxford University Press.

Goldman, A. I. (2010), "Why Social Epistemology is Real Epistemology", in Haddock, A., Millar, A., and Pritchard, D. (eds.), Social Epistemology, New York: Oxford University Press.

Goldman, A. I. (2012). Reliabilism and contemporary epistemology essays. New York, N.Y: Oxford University Press. 
Goldman, A., \& Blanchard, T. (2001, February 26). Social epistemology. Retrieved February 04 2021,

from https://stanford.library.sydney.edu.au/archives/sum2016/entries/epistemology-social/

Goldman, A., \& O'Connor, C. (2019, August 28). Social epistemology. Retrieved February 04, 2021, from https://plato.stanford.edu/entries/epistemology-social/

Goldman, A., Blanchard, T., (2018). Social epistemology. In Edward N. Zalta, editor, The Stanford Encyclopedia of Philosophy. Metaphysics Research Lab, Stanford University, summer 2018 edition, 2018

Hilary, M. (2015). Epistemology: A Contemporary Approach,

Kush, M. (2016). Social Epistemology, in Metaepistemologcal Issues.

Mills, J. S. (1962). On Liberty, Reprinted Edition, Hardway Press.

New York: Oxford University Press.

Phillips, D. C. (2000). The expanded social scientist's bestiary: A guide to fabled threats to, and defenses of, naturalistic social science. Lanham Maryland: Rowman \& Littlefield.

Rorty, R. (1979). Philosophy and The Mirror of Nature, Blackwell.

Roy, C. (2016). Social Dimension of Knowledge, Parkwell.

Sarachukwuaka, E. (2017). Basic Issues in Epistemology, Larry-Chris.

Shapin, S. (1994). A Social History of Truth, University of Chicago Press.

Zanzy, B. (2015). Introductory Approach To Epistemology, Phoenix. 


\section{6| Predestinasi}

Volume 13, No. 1, Juni 2020 Hal. 15- 26 